\title{
Relationship Between Group Process Variables and Group Performance in the IT Sector
}

\author{
Vishnupriya. D, Samudhra Rajakumar. C
}

\begin{abstract}
Different types of group process variables- trust, group cohesion, group social interactions and group potency are analysed for its relationship with group performance in Information Technology (IT) sector. The group includes 250 members working in 50 self-managed groups for 45 days period. Two independent variables- task completion and work efficiency are considered for assessing group performance. A set of hypothesis is predicted to analyse the relation of the variables with the performance. It is found that the selected group process variables are related to each of the group process variables. Among the four group process variables studied, group potency is proved to be the highest potential variable for an effective group performance.
\end{abstract}

Keywords: group performance, group potency, group cohesion, leadership, task completion, self-efficacy

\section{INTRODUCTION}

Information technology sector demands high tech technical operations to reach the aimed performance level (Tippins\&Sohi, 2003). Making sure of the technical capability of the group resource is done with an effective designed information system's technical capability (CepedaCarrion et al., 2012). Subsequently, team resource contributes more towards the improvement of information system capabilities, showcasing two wide characteristic features such as specificity and skill set. Specificity refers to the wide knowledge about the tasks in a firm and skill set indicates the self-possession (Ravichandran\&Lertwongsatien, 2005). Technical capabilities include system analysis, advanced technical knowledge, designing for a problem and programming (Bharadwaj, 2000). The mentioned characteristic features actively engage the group members in a firm for quick communication and easy exchange of knowledge. Knowledge in programming capabilities stems up the working communities confident to work in wide environments (Feeny\& Willcocks, 1998). Providing the autonomy to group's with assigned sharing tasks can induce the working environment collaboration, causing the leverage of technical skills and established socio-technical network (Bharadwaj, 2000).Administrative ability drives the ability to identify and integrate the information sector system's capability (Wang et al., 2015). Information sensing, collecting, organising and disseminating the information is properly accessed through the organization's administrative capability (Mithas et al., 2011). Administrative duties can be enhanced by allotting leadership (Feeny\& Willcocks, 1998). Organizing the technologies and scheduling the tasks within

Vishnupriya. D, Research Scholar, Department of Business Administration, Annamalai University, Tamilnadu, India.

Samudhra Rajakumar. C, Professor, Department of Business Administration, Annamalai University, Tamilnadu, India.
Revised Manuscript Received on September 10, 2019.

and coordination with other entities are parts of an administration side (Chen \& Wu, 2011; Aydiner et al., 2019).

Improvisation in an organization's quality, productivity and customer satisfaction is vital, and it seems to be major focus of groups. Organization growth is directly proportional to group performance, and the growth map increases with group activities (Guzzo and Salas, 1995; Jordan et al., 2002). Especially in Information Technology sector, group-based structures are built with varied groups for enhancing the economically strategic business module. Group effectiveness can be assessed using three parametersgroup performance, long term group viability and group member participation. Performance of a group includes subjective assessments and objective group performance (Banumathi and Samudhra Rajakumar ,2015). Long term viability indicates the maintenance of good relationship between the group members. Group member satisfaction points out the task completion, inspite of the negative experiences (Jordan et al., 2002).

The importance of various group process variables such as group potency, group cohesiveness (Barrick et al., 1998) and group member exchange (Liden et al., 2000) have been analysed. Research on implicating the relationship between group process variables and group performance in the IT sector is found to be scarce, and hence this research investigation is done.

This investigation mainly focuses on the analysis of the influence of group process variables- trust, group cohesion, group social interaction and group potency in achieving the work efficiency and task completion by inducing the group performance. Individually, the process variables and their relation to group performance are studied. Fig. 1. represents the general framework of this study.

\section{THEORETICAL BACKGROUND AND HYPOTHESES}

Building a successful system requires maintaining positive relationships with the group members for accomplishing the project related goals (Ozer \& Vogel, 2015). Fig. 2 represents the conceptual framework of the relationship between the process variables and performance based on the hypothesis.

\section{Group performance}

Group performance can be influenced and affected by many factors. The factors include group effort, productivity and goal achievement. Productivity represents the output 
produced by the group. The output may be a decision taking, service-oriented or product generation. Exactly, the performance index is decided by the customer or client satisfaction. If the output generated is not satisfactory, then the group performance goal is not achieved, and the group is not effective too. It is necessary to consider group viability, group member satisfaction, task completion and work efficiency as parameters for analysing group performance.

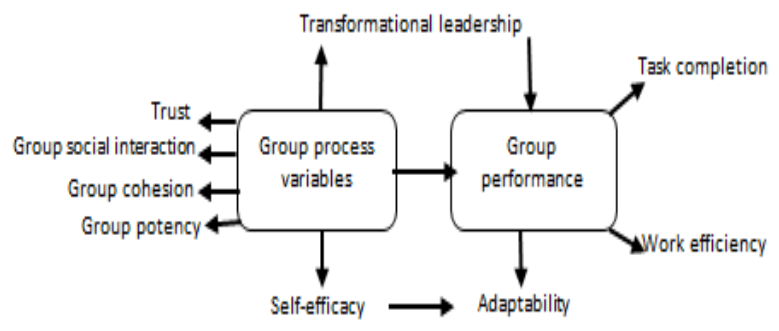

Fig 1 General framework of the current investigation

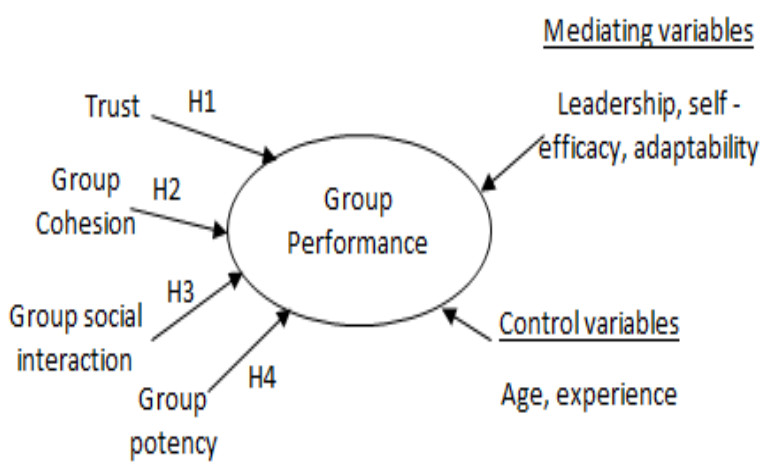

\section{Fig 2 Relationship between the process variables and} performance based on the hypothesis

The present study is focussed on group performance measures- task completion and work efficiency.

\section{Trust}

Trust and confidence in peer members gradually outcomes the emotional stress by proper communication, paving to better group performance. Increase in growth of an organization, increases the trust and it can be induced by using the emotional intelligence (Rezvani et al., 2019; Rezvani et al., 2018) and based on this research, the following hypothesis is suggested:

H1. Trust optimistically influences group performance.

\section{Group cohesion}

It is represented as the culmination of forces that attracts the group members to stay in a group. Group cohesion is considered as a construct with varying relationship between group performance and group cohesion. The following hypothesis is predicted according to the research findings:

H2. Group cohesion optimistically influences group performance.

\section{Group social interaction}

Group social interaction plays a crucial role in active group participation and its corresponding performance. Social interaction paves the way for exchanging ideas, sharing their valuable feedback and assisting the group members. Recognition, gaining information and assistance is possible only through group social interaction. Interaction between the group members is related to group performance, and it is a good forecast of institutional commitment and work satisfaction (Banumathi and Samudhra Rajakumar ,2016). According to the research studies, group social interaction is predicted to be a good indicator for successful group performance, and hence the following hypothesis is suggested:

H3. Group level social interaction optimistically influences the group performance

\section{Group potency}

Group potency is a positive group effective process variable. It is the strong belief that is placed within the group members for task completion. It sustains the shared belief of performing successfully within the group members. Group potency and group performance are inter-related (Gibson et al., 2000), accompanied by a wide variety of tasks such as scrum call attending, evening call schedule attending, daily status call, participating in meeting, mail checking, submitting the prescribed task etc. (find studies related to this). From these findings, the following hypothesis is predicted:

H4. Group potency of group optimistically influences group performance.

Relationship between the individual group process variables is analysed for predicting the efficiency of group performance. Beyond this, the influence of clustered group process variables and its correlation with group performance too should be analysed and based on this, the following hypothesis is proposed:

H5. Trust, group cohesion, group social interaction and group potency will describe the differences or unique variance in group performance.

\section{RESEARCH METHODOLOGY}

\section{Collection of group-level response}

Collecting group-level response is possible only after getting an individual-level response. Calculating the arithmetic mean of all the individual's responses together constitute the group level response. The scores obtained individually showcases the group-level parameters. To be specified, the group process variables are provided with a particular score, and the individual scores are subjected to calculate the arithmetic mean scores of all the responses (Gibson et al., 2000). The group members include test analyst, system analyst, senior system analyst, software engineer and software trainee of ages between 25 and 35 years and of different genders. Altogether 25 groups are selected. Each group constitutes 5 members, and the group is led by group leaders, who performs the role of leadership in achieving group performance. A task is allotted to each group members by the group lead and the input provided to the members are actively watched by the lead for successful task completion. Success is possible only through the 
performance of group with high focus towards the input given to the group members and their involvement in group with application of both mental task and physical task. Perfect planning must be laid out, and proper execution of all the inputs is a need to be emphasised. So, the best possible way to cluster individual-level response to grouplevel performance is arithmetic mean method.

\section{Survey setting and data collection}

System analysts $(\mathrm{N}=250)$ working in a particular project is utilized for this investigation. All the analysts are assigned to be in a particular group, led by group leads. A group includes 5 participants, and the complete study is done for 45 days. Each group lead observes and co-ordinates the group for attaining their goals. The experimental subjects are full-time workers with an average age of 31 and average experience of 6 years. About $65 \%$ were male subjects. All the groups are included in the self-managing group with power to achieve the task to be completed. Each group is responsible for the resources to be utilized and issues concerned within the group members.

For 45 days, two different types of surveys are done. Questionnaires are put forward towards the group members with a scale rating of 5-point, a Likert type scaling rate (1 representing not at all true to 5 representing very true). The first point representing the option-strongly disagree and point 6 represents the strongly agree option. Variables that are not concerned for this study are collected in the first survey and the second type of survey concentrates on the group process variables- trust, group cohesion, group social interaction and group potency. The second survey is obtained in the last week of this experimental study. Group lead survey is scheduled at the last week for assessing the subjective group performance. From $2^{\text {nd }}$ week to last week, objective group performance was surveyed.

\section{Measurements: group process variables}

Table 1, 2, 3 and 4 list outs the various scales used for measuring

\section{Trust}

Trust scale of five-item was used for analysis (Cook and Wall, 1980). Trust scale is fitted with high-end psychometric parameters (Costa \& Anderson, 2011).

\section{Group cohesion}

Group cohesion explains the valuable interaction among the group members. The interactions include the conflict resolution identifying, effective communication and sharing the workload. It can be measured on a scale containing four items (Seers, 1989). The increased score for group cohesion represents the positively effective interaction between the group members.

\section{Group social interaction}

It acknowledges the relationship between the group members and it can be executed only with the aid of communication and sharing the ideas or views. A ten-item scale is used to measure this group process variable (Seers, 1989). The increased score indicates the perceived quality of communication relationship within the individual members and also as a group.

\section{Group potency}

Provided with different types of tasks, group members will start focussing towards the work for obtaining better group performance, generally termed as group potency, and it is calculated using a seven-item scale. Increased group potency score indicated increased group performance, having the capability to do varied tasks.

\section{Measurement: Group Performance variables}

Group performance was assessed with two performance variables gathered from each group's over 45 days. All those parameters are analysed and mentioned.

\section{Task Completion and Work efficiency}

Each group were assigned with a task, and the rate of accomplishment is noted as scores. The tests include dynamicity, group work, etc. The obtained individual scores are subjected to arithmetic mean calculation for obtaining the average score for the group performance.

\section{Measurement: Mediating variables}

\section{Transformational Leadership}

Group work with pertinent communication is exercised through proper leadership. If a task is assigned to solve a problem, two sets of periods are analysed. The first set of period is the planning period, during which the problem evaluation is done, and a plan is developed. In the second set of period, the developed plan is executed. In realistic phase, the problem is placed, and the solution is arrived with concrete discussion and communication.Group leader act as a mentor and he is responsible for identifying the skill set of group members before assigning the task. The scores were assigned based on the two parameters- time is taken for task completion and successful reproducibility. The maximum score is fixed as 10 , and it is calculated for all the groups, irrespective of the task assigned. Empowerment leadership over the IT techs is a necessity (Windeler et al., 2017). Techs personality and characters of group lead are factors that influence the performance report. Emotional intelligence of a team lead is effective for attributing the group performance score (Cruz et al., 2015; Khosravi, 2017; Rezvani et al., 2019).

\section{Self-efficacy}

Self-efficacy intensifies the group efficacy, strengthens the group performance, escalating the process of task completion. Group efficacy relates to the shared belief for enacting an action (Lin et al., 2014).

\section{Adaptability}

Adaptability is a capacity to handle various types of emotional stresses, emerging due to an individual's view on their capabilities in responsibility management (Blascovich, 2008). Adaptability is imperative for constructive team performance (Rezvani et al., 2019) 


\section{Measurement: Control variables}

Age and experience are considered as the control variables. In group participation, gents are more involved than the females

\section{Aggregation to group-level data}

Solo responses from each member are gathered together, and the data are aggregated to group-level data. It is important to be noted; the response being different may hinder the aggregation of individual-level data ratings. Among the groups, interrater agreement statistic $\left(\mathrm{r}_{\mathrm{wg}}\right)$ was determined for all considered group process variables (Banumathi and Samudhra Rajakumar , 2015). The results imprint the involvement of group members, and if the predicament value is so less for all the group process variables, it showcases the elimination of those group members from the study. From the obtained calculations, the mean value for the interrater agreement statistic is found to be $0.9 r_{\mathrm{wg}}, 0.8 \mathrm{r}_{\mathrm{wg}}, 0.6 \mathrm{r}_{\mathrm{wg}}, 0.9$ for trust, group cohesion, group social interaction and group potency respectively.

\section{DATA ANALYSIS AND RESULTS}

The predicted hypothesis 1, 2, 3 and 4 are tested using correlation analysis. Hypothesis 5 is being tested with hierarchical regression analysis. Variance in the group performance measures concerning hypothesis 5 is assessed using usefulness analysis. All the independent variables are used for regression model analysis in measuring group performance.

Mean, SD, inter-correlation and coefficient alphas for control, process, mediating and outcome variables are shown in Table 4. For transformational leadership, Scores ranges from 8 to 35 points in each group $(\mathrm{M}=20.56, \mathrm{SD}=$ 5.43). For task completion, Moderate relation exists between the performance tests $(\mathrm{r}=0.38, \mathrm{p}<.01)$. Positive answer for all the items are scored, and the scores are obtained in the range of 85.56 to $96.22(\mathrm{M}=91.32, \mathrm{SD}=1.35)$.

Table 1 Trust and its corresponding points

\begin{tabular}{|l|l|}
\hline Trust item & $\begin{array}{l}\text { Alpha } \\
\text { point }\end{array}$ \\
\hline Belief in individuals by a team lead & 0.45 \\
\hline Emotional intelligence & 0.51 \\
\hline Encouraging peer relations & 0.32 \\
\hline Proper communication & 0.21 \\
\hline Supportive relation & 0.45 \\
\hline
\end{tabular}

Table 2 Cohesion item and its corresponding points

\begin{tabular}{|l|l|}
\hline Cohesion item & $\begin{array}{l}\text { Alpha } \\
\text { point }\end{array}$ \\
\hline Mingling with the group members & 0.81 \\
\hline Free time discussions & 0.73 \\
\hline Adoption to changes & 0.56 \\
\hline Training & 0.76 \\
\hline
\end{tabular}

\section{points}

\begin{tabular}{|l|l|}
\hline Group social interaction item & $\begin{array}{l}\text { Alpha } \\
\text { point }\end{array}$ \\
\hline $\begin{array}{l}\text { Group members encouraging individual's } \\
\text { capability }\end{array}$ & 0.811 \\
\hline Flexible HR policies & 0.89 \\
\hline Mutual support & 0.51 \\
\hline Mutual respect & 0.76 \\
\hline Morale & 0.42 \\
\hline Sharing valuable information & 0.19 \\
\hline Planning & 0.94 \\
\hline Productivity & 0.80 \\
\hline Internal focus & 0.54 \\
\hline Integrity and unity & 0.78 \\
\hline
\end{tabular}

Table 4 Group potency item and its corresponding points

\begin{tabular}{|l|l|}
\hline Group potency item & $\begin{array}{l}\text { Alpha } \\
\text { point }\end{array}$ \\
\hline $\begin{array}{l}\text { The belief of a group for its excellent } \\
\text { delivery of output }\end{array}$ & 0.90 \\
\hline Stability & 0.85 \\
\hline Predictability & 0.56 \\
\hline Technical knowledge & 0.73 \\
\hline Entrepreneurship & 0.45 \\
\hline Response to External environment changes & 0.12 \\
\hline Task clarity & 0.91 \\
\hline
\end{tabular}


Table 5 Descriptive statistics and inter-correlations

\begin{tabular}{|c|c|c|c|c|c|c|c|c|c|}
\hline \multicolumn{3}{|l|}{ Variables } & \multirow{2}{*}{$\begin{array}{l}\text { Mean } \\
12.10\end{array}$} & \multirow{2}{*}{$\begin{array}{l}\begin{array}{l}\text { Standard } \\
\text { Deviation }\end{array} \\
7.54\end{array}$} & \multirow[b]{2}{*}{$-{ }^{\mathrm{a}}$} & \multirow[t]{2}{*}{2} & \multirow[t]{2}{*}{3} & \multirow[t]{2}{*}{4} & \multirow[t]{2}{*}{5} \\
\hline \multirow{4}{*}{$\begin{array}{l}\text { Control } \\
\text { variables }\end{array}$} & \multirow[t]{2}{*}{ Experience } & Male & & & & & & & \\
\hline & & Female & 8.98 & 4.67 & $-{ }^{\mathrm{a}}$ & & & & \\
\hline & \multirow[t]{2}{*}{ Age } & Male & 35.52 & 7.91 & 0.3 & $-{ }^{\mathrm{a}}$ & & & \\
\hline & & female & 31.41 & 6.8 & 0.5 & $-{ }^{\mathrm{a}}$ & & & \\
\hline \multirow{4}{*}{$\begin{array}{l}\text { Process } \\
\text { variables }\end{array}$} & \multicolumn{2}{|l|}{ Trust } & 0.52 & 0.09 & 0.31 & 0.45 & -0.56 & -.24 & 0.62 \\
\hline & \multicolumn{2}{|c|}{ Group cohesion } & 0.86 & 0.1 & 0.02 & $-.02 *$ & $0.61 * *$ & & \\
\hline & \multicolumn{2}{|c|}{ Group social interaction } & 0.75 & 0.08 & 0.09 & -.16 & 0.94 & & \\
\hline & \multicolumn{2}{|c|}{ Group potency } & 0.98 & 0.13 & 0.17 & -.38 & $.52 * * *$ & $0.79 * * * *$ & 0.92 \\
\hline \multirow[t]{3}{*}{$\begin{array}{l}\text { Mediating } \\
\text { variables }\end{array}$} & \multicolumn{2}{|c|}{$\begin{array}{l}\text { Transformational } \\
\text { leadership }\end{array}$} & 20.56 & 5.43 & 0.12 & 0.23 & $0.31 *$ & $0.59 * *$ & \\
\hline & \multicolumn{2}{|c|}{ Self-efficacy } & 5.10 & 1.10 & 0.9 & 0.8 & 0.72 & 0.63 & -.25 \\
\hline & \multicolumn{2}{|c|}{ Adaptability } & 4.3 & 1.02 & 0.2 & -.81 & & & \\
\hline \multirow{2}{*}{$\begin{array}{l}\text { Outcome } \\
\text { variables }\end{array}$} & \multicolumn{2}{|c|}{ Task completion } & 91.32 & 1.35 & -.16 & 0.23 & $0.45^{* * *}$ & $0.61 * * *$ & 0.78 \\
\hline & \multicolumn{2}{|c|}{ Work efficiency } & 82.5 & 1.05 & 0.12 & 0.24 & $-.02 *$ & $-0.71 * * * *$ & 0.91 \\
\hline
\end{tabular}

a. no information

$$
* * p<0.5, * * * p<0.1, * * * * p<0.0
$$

\section{Hypothesis testing}

Table 5 depicts the hypothesis 1, 2, 3, 4 tested results with high significant values for group potency, and it shows the higher relationship with the group performance.

\section{DISCUSSION}

Main goal of this investigation is to (a) identify relationship between the group process variables- trust, group cohesion, group social interaction and group potency with that of the group performance measures- task completion and work efficiency (b) quantifying the individual and collective assessment of group process variables for an efficacious group performance in IT sector.

\section{Specific findings}

\section{Study Limitations}

The limitation exists in the small sample study where only $\mathrm{N}=50$ groups are considered, and it is relatively small for considering different types of group process variables (Jordan et al., 2002). In this present study, group process variables like group potency, group cohesion and group social interaction come out with high statistical value supporting the predicted hypothesis confidently. But the other variable- trust originates with low statistical power suggesting the need for high sample requirement. Obtaining some types of data from the sponsoring organization is also hindered on some occasions.

\section{Study strengths}

The entire investigation was done in a field setting. All the participants were provided with a group. Group performance criteria are diverse, and its practicality application is noteworthy to be significant. Individually, the outcomes of group performance measures of each participant were analysed both objectively and subjectively. High efficient group performance is expected with increased participation and with maximum likelihood. Group leader's ratings are a typical predicament with valid measures, induced by various inputs. Diversified group performance criteria increase the strength of the experimental study. The obtained results support the previous research suggesting group potency with reliable advantages over the other process variables (Jordan et al., 2002). During the group development timing, attention should be given for attaining a high group potency, thereby ensuring a successful group achievement. Co-operation and valuable communication are the forerunners for group potency.

\section{CONCLUSION}

The vital part of this study lies in amplifying the importance of the relationship between the group process variables- trust, group cohesion, group social interaction and group potency with the group performance measures- task completion and work efficiency in association with the transformational leadership, self-efficacy and adaptability. Critically, all the group process variables have specific influence over the efficiency of group performance. Among the group process variables considered, group potency strongly favours the group performance. Group social interactions and group cohesion are equally placed in a perfect line than the trust process variable that is placed at least importance. Self-efficacy with adaptability in a group is quite required for sustained group-level performance. Subsequently, transformational leadership plays a keen role in analysing the individualized skills, subjecting to fit each group member in a perfect task. Group performance measures- task completion and work efficiency scores met the group potency process variable with a maximum relationship. Future studies can be done on the side of identifying the reciprocal relationships with novel process variables consideration. 


\section{REFERENCES}

1. Barrick, M. R., Stewart, G. L., Neubert, M. J., \& Mount, M. K. (1998). Relating member ability and personality to work-team processes and team effectiveness. Journal of Applied Psychology, 83, 377-391.

2. Guzzo, R. A., \& Salas, E. (1995). Team effectiveness and decision making in organizations. San Francisco: JosseyBass.

3. Gibson, C. B., Randel, A. E., \&Earley, P. C. (2000). Understanding group efficacy: An empirical test ofmultiple assessment methods. Group\&Organization Management, 21, 67-97.

4. Liden, R. C.,Wayne, S. J.,\&Sparrowe, R.T. (2000).Anexamination ofthe mediating role of psychological empowerment on the relations between the job, interpersonal relations, and work outcomes. Journal of Applied Psychology, 85, 407-416.

5. Seers, A. (1989). Team-member exchange quality: A new construct for role-making research. Organizational Behavior and Human Decision Processes, 43, 118-135.

6. Jordan, M., Field, H., Armenakis, A. (2002). The relationship of group process variables and team performance: A team level analysis in a field setting. Small Group Research, 33(1), 121-150.

7. Bharadwaj, A. S. (2000). A resource-based perspective on information technology capability and firm performance: An empirical investigation. MIS Quarterly, 24(1), 169-196.

8. Cepeda-Carrion, G., Cegarra-Navarro, J. G., \& JimenezJimenez, D. (2012). The effect of absorptive capacity on innovativeness: Context and information systems capability as catalysts. British Journal of Management, 23(1), 110-129.

9. Chen, Y.-C., \& Wu, J. H. (2011). IT management capability and its impact on the performance of a CIO. Information \& Management, 48(4-5), 145-156.

10. Feeny, D. F., \& Willcocks, L. P. (1998). Core IS capabilities for exploiting information technology. Sloan Management Review, 39, 9-21.

11. Mithas, S., Ramasubbu, N., \&Sambamurthy, V. (2011). How information management capability influences firm performance. MIS Quarterly, 35(1), 237-256.

12. Ravichandran, T., \&Lertwongsatien, C. (2005). Effect of information systems resources and capabilities on firm performance: A resource-based perspective. Journal of Management Information Systems, 21(4), 237-276.

13. Tippins, M. J., \&Sohi, R. S. (2003). IT competency and firm performance: Is organizational learning a missing link? Strategic Management Journal, 24(8), 745-761.

14. Wang, Y., Shi, S., Nevo, S., Li, S., \& Chen, Y. (2015). The interaction effect of IT assets and IT management on firm performance: A systems perspective. International Journal of Information Management, 35(5), 580-593.

15. Aydiner, AS., Tatoglu, E., Bayraktar, E., Zaim, S. (2019). Information system capabilities and firm performance: Opening the black box through decisionmaking performance and business-process performance, Int. J. Inf. Manage., 47, 168-182.

16. Rezvani, A., Khosravi, P. (2019). Emotional intelligence: The key to mitigating stress and fostering trust among software developers working on information system projects. International Journal of Information Management, 48, 139-150.

17. Blascovich, J. (2008). Challenge, threat, and health. In J. Y. Shah, \& W. L. Gardner (Eds.). Handbook of Motivation Science (pp. 481-493). New York, NY: US: The Guilford Press.

18. Banumathi and Samudhra Rajakumar (2015) "Relationship between Corporate Enterpreneurship and Emotional Intelligence", Indian Journal of Applied Researc, Vol.5, and Issue :9.p 6201-6205
19. Banumathi and Samudhra Rajakumar (2015) "The Role of Middle Level managers and Enterpreneurship", International Journal of Arts , Humanities and Management studies, Volume 01, No.9, pp-21-26

20. Banumathi and Samudhra Rajakumar (2016) " Factors influencing work discretion " of corporate entrepreneurship: An empirical study, Asian Journal of Multidimensinal Research (AJMR) Volume :5, Issue :2

21. Cook, J., \& Wall, T. (1980). New work attitude measures of trust, organizational com- mitment and personal need non-fulfilment. Journal of Occupational Psychology, 53, 39-52.

22. Costa, A. C., \& Anderson, N. (2011). Measuring trust in teams: Development and vali- dation of a multifaceted measure of formative and reflective indicators of team trust. European Journal of Work and Organizational Psychology, 20(1), 119-154.

23. Cruz, S., da Silva, F. Q., \&Capretz, L. F. (2015). Forty years of research on personality in software engineering: A mapping study. Computers in Human Behavior, 46,94-113.

24. Khosravi, P., Rezvani, A., \& Ahmad, M. N. (2013). Does Organizational Identification Lead to Information System Success? World Applied Sciences Journal, 21(3), 402408.

25. Ozer, M., \& Vogel, D. (2015). Contextualized relationship between knowledge sharing and performance in software development. Journal of Management Information Systems, 32(2), 134-161.

26. Windeler, J. B., Maruping, L., \&Venkatesh, V. (2017) Technical systems development risk factors: The role of empowering leadership in lowering developers' stress. Information Systems Research, 28(4), 775-796.

27. Rezvani, A., Khosravi, P., \&Ashkanasy, N. M. (2018). Examining the interdependencies among emotional intelligence, trust, and performance in infrastructure projects: A multilevel study. International Journal of Project Management, 36(8), 1034-1046.

28. Lin, CW., Lin, CS., Huang, P., Wang, Y. (2014). How group efficacy mediates the relationship between group affect and identification. Journal of Business research, 67, 1388-1394.

\section{AUTHORS PROFILE}

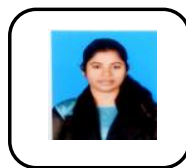

Vishnupriya. C is a Research Scholar pursuing research in Annamalai University. His research area is focused on Relationship Between Group Process Variables And Group Performance In The IT Sector

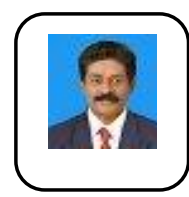

Samudhra Rajkumar. $\mathrm{C}$ is Professor and Head ofthe Department of Business Administration, Annamalai university. He is a recipient of "BEST TEACHER" award twice. Also, he has received "BEST RESEARCH PAPER" award at Hungary. He has visited several countries to participate in conferences. He has conducted workshops on "NONLECTURE METHOD and organized SIMULATED BUSINESS GAMES". He is speciliased in Marketing and Corporate Entrepreneurship. He has completed many research projects and consultancy for corporates 